\title{
Review of neural rehabilitation programs for dyslexia: how can an allophonic system be changed into a phonemic one?
}

\author{
Willy Serniclaes ${ }^{1,2}$ *, Gregory Collet ${ }^{2}$ and Liliane Sprenger-Charolles ${ }^{3}$ \\ ${ }^{1}$ Laboratoire Psychologie de la Perception (UMR 8242), Centre National de la Recherche Scientifique and Université Paris Descartes, Paris, France \\ 2 Unité de Recherche en Neurosciences Cognitives, Centre de Recherche en Cognition et Neurosciences, Université Libre de Bruxelles, Brussels, Belgium \\ ${ }^{3}$ Laboratoire de Psychologie Cognitive (UMR 7920), Centre National de la Recherche Scientifique and Aix-Marseille Université, Marseille, France
}

Edited by:

Julie Chobert, Centre National de la

Recherche Scientifique, France

Reviewed by:

Thomas Lachmann, University of

Kaiserslautern, Germany

Joseph Krummenacher,

Ludwig-Maximilians-Universität

München, Germany

*Correspondence:

Willy Serniclaes, Laboratoire

Psychologie de la Perception

(UMR 8242), Centre National de la

Recherche Scientifique and

Université Paris Descartes,

45 Rue des Saints Pères,

75006 Paris, France

e-mail: willy.serniclaes@

parisdescartes.fr
Neural investigations suggest that there are three possible core deficits in dyslexia: phonemic, grapho-phonemic, and graphemic. These investigations also suggest that the phonemic deficit resides in a different mode of speech perception which is based on allophonic (subphonemic) units rather than phonemic units. Here we review the results of remediation methods that tap into each of these core deficits, and examine how the methods that tap into the phonemic deficit might contribute to the remediation of allophonic perception. Remediation of grapho-phonemic deficiencies with a new computerized phonics training program (GraphoGame) might be able to surpass the limits of classical phonics training programs, particularly with regard to reading fluency. Remediation of visuo-graphemic deficiencies through exposure to enhanced letter spacing is also promising, although children with dyslexia continued to read more slowly than typical readers after this type of training. Remediation of phonemic deficiencies in dyslexia with programs based solely on phonemic awareness has a limited impact on reading. This might be due to the persistence of a covert deficit in phonemic perception. Methods based on slowed speech enhance the perception not only of phonemic features but also of allophonic features, and this is probably why they have not been found to be effective in meta-analyses. Training of phonemic perception with a perceptual fading paradigm, a method that improves precision in identification and discrimination around phonemic boundaries, has yielded promising results. However, studies with children at risk for dyslexia and dyslexic adults have found that even when behavioral data do not reflect allophonic perception, it can nevertheless be present in neural recordings. Further investigations should seek to confirm that the perceptual fading paradigm is beneficial for reading, and that it renders perception truly phonemic.

Keywords: dyslexia, determinants of dyslexia, allophonic perception, rehabilitation, perceptual fading

\section{THE THREE SOURCES OF DYSLEXIA}

Developmental dyslexia is a specific learning disability characterized by difficulties in the acquisition of low-level reading skills: i.e., accurate and/or fluent word recognition and decoding skills (Lyon et al., 2003). Developmental dyslexia affects about 5-10\% of the population (Shaywitz et al., 1990; Peterson and Pennington, 2012). Low-level reading skills, especially decoding skills, are chiefly a matter of relating the basic units of the written language (letters and groups of letters called graphemes) to the basic units of the spoken language (phonemes). Children with dyslexia experience great difficulties in learning grapheme-phoneme associations and, once acquired, these associations remain suboptimal (Lachmann and van Leeuwen, 2014). Dyslexic children do not read fluently and expend much more energy in reading than typical children (Shaywitz and Shaywitz, 2005; Sprenger-Charolles et al., 2006; Blomert and Vaessen, 2009).
The most obvious possible reason for dyslexics' problem in establishing grapheme-phoneme relationships is a deficiency in cross-modal neural mechanisms (Blomert, 2011). Evidence of areas responsive to the simultaneous presentation of letters and speech sounds in the temporal cortex (superior temporal sulcus, STS and superior temporal gyrus, STG) has been presented. Furthermore, it has been shown that when a letter and sound occur within the same narrow time-window, letters influence the processing of speech sounds (van Atteveldt et al., 2004). This and other related findings (Blomert and Froyen, 2010) suggest that letter-sound integration is performed by specialized neural processes. Such cross-modal integration also occurs in dyslexic children with 4 years of reading instruction, but the influence of print on sound perception is much weaker for them than for agematched controls, and it only appears when the letter is presented much earlier than the sound (Froyen et al., 2011). 


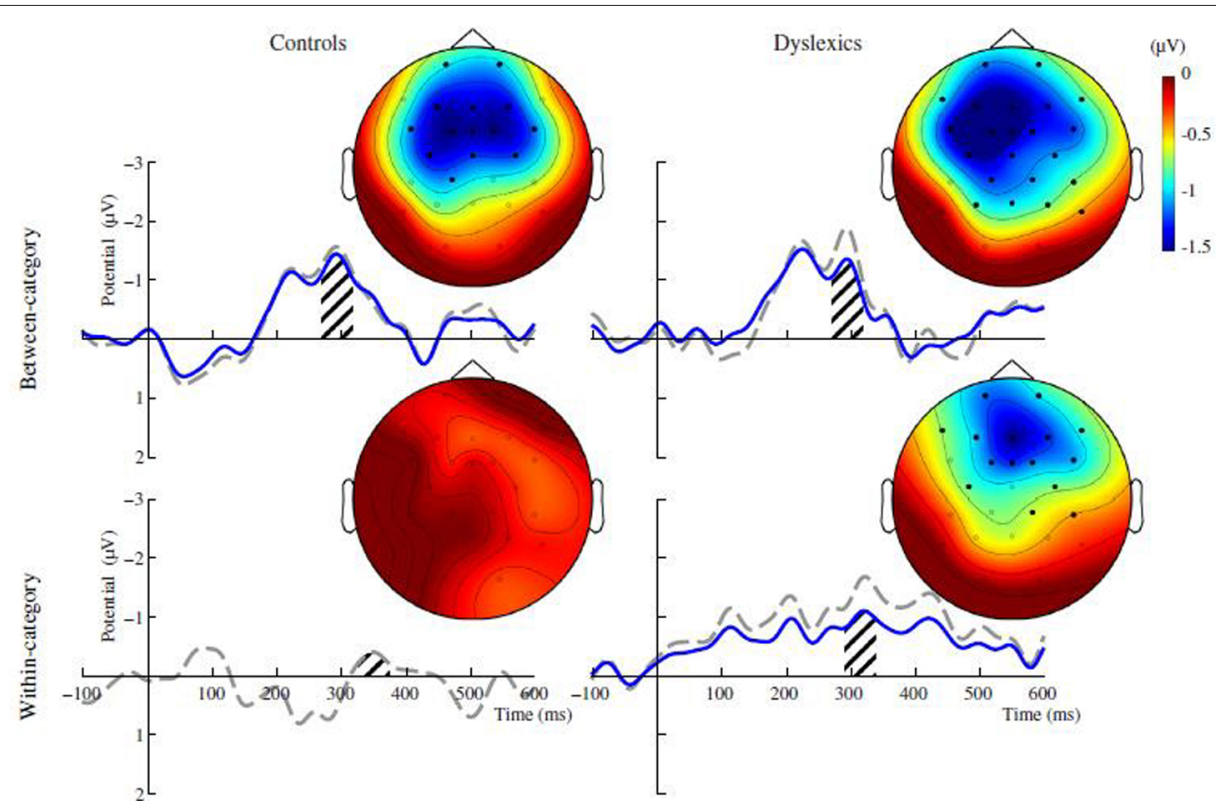

FIGURE 1 | Mismatch negativity (MMN; a pre-attentive neurophysiological response, a component of the event-related potential) for a phonemic contrast (above) and for an allophonic contrast (below) in adult dyslexics (right) and controls (left). Adapted from Noordenbos et al. (2013, Figure 3).

A specific failure in the simultaneous binding of letters with speech sounds is not the only possible cause of dyslexia, however. There are two other main reasons why grapheme-phoneme associations might be deficient in the absence of specific binding problems. The first factor that might also affect graphemephoneme associations is a deficiency in the visual processing of letters ${ }^{1}$. This hypothesis has been formulated in various different ways, and might be explained in the framework of a recent theory (the "neuronal recycling hypothesis": Cohen and Dehaene, 2004; Dehaene, 2014). The theory attributes fluent word recognition to a specific brain area of the left hemisphere [dubbed the "visual word form area (VWFA)"], which was initially devoted to visual processing requiring a level of acuity similar to that needed by letter processing but which, in recent human history, has been recycled for letter perception. However, a recent survey indicates that, besides being used for visual word perception, the VWFA has maintained its original function in processing other visual stimuli (Vogel et al., 2014; see also Dehaene, 2014). Vogel et al. (2014) also noted evidence that activity in the occipito-temporal cortex is strongly correlated with the dorsal attentional network. This is in accordance with several studies that point to the role of visuo-attentional deficits in part of the dyslexic population (e.g., Franceschini et al., 2012; Lobier et al., 2012).

A second factor that might also affect grapheme-phoneme associations is a deficiency in the phonological processing of

\footnotetext{
${ }^{1}$ One of the possible indicators of a visual source of dyslexia is the absence of problems in non-word reading, which is fairly rare in the dyslexic population (see Sprenger-Charolles et al., 2011, for a review of the literature, with a metaanalysis of 300 cases of dyslexics). However, the phonological deficit might be a secondary consequence of a more basic visual deficit, and there are also positive indicators of visual problems, such as those in parallel letter-string processing (Lobier et al., 2012).
}

speech sounds. Children with dyslexia often exhibit a lack of phonemic awareness: i.e., a problem with the ability to segment words into phonemes, a skill which is required to learn to read in an alphabetic system, but not required to learn to speak (Liberman et al., 1974). A deficit in phonemic awareness might be responsible for difficulties in relating these units to graphemes (for a review, Melby-Lervåg et al., 2012). However, the deficit in phonemic awareness is probably the consequence of a more drastic difference in the mode of speech perception. Perceiving speech sounds in terms of subphonemic units (allophones) induces serious problems for relating them to phoneme-sized graphical units. This is the possibility raised by the "allophonic" theory of dyslexia (Serniclaes et al., 2004).

There is growing evidence that individuals with dyslexia discriminate between allophonic variants of the same phoneme, whereas typical-reading controls do not perceive such distinctions (Bogliotti et al., 2008; Noordenbos et al., 2012a,b, 2013, for a comprehensive review of the available evidence; Serniclaes and Sprenger-Charolles, 2015). Even when there is apparently no behavioral manifestation of allophonic discrimination (e.g., Messaoud-Galusi et al., 2011), it can nevertheless be present in the brain. This has been evidenced by the results of studies conducted in Dutch with either children at risk for dyslexia or adults with dyslexia (Noordenbos et al., 2012b, 2013; see Figure 1). The lack of a behavioral manifestation of allophonic processing, that in fact takes place at the neural level, suggests the involvement of inhibitory processes. Such processes would inhibit the neural responses to allophonic contrasts so that only the neural responses to phonemic contrasts would be available for emitting the behavioral responses. According to a PET study with French adults with dyslexia, such processes might take place in the frontal cortex in the inferior frontal gyrus (IFG) close to 


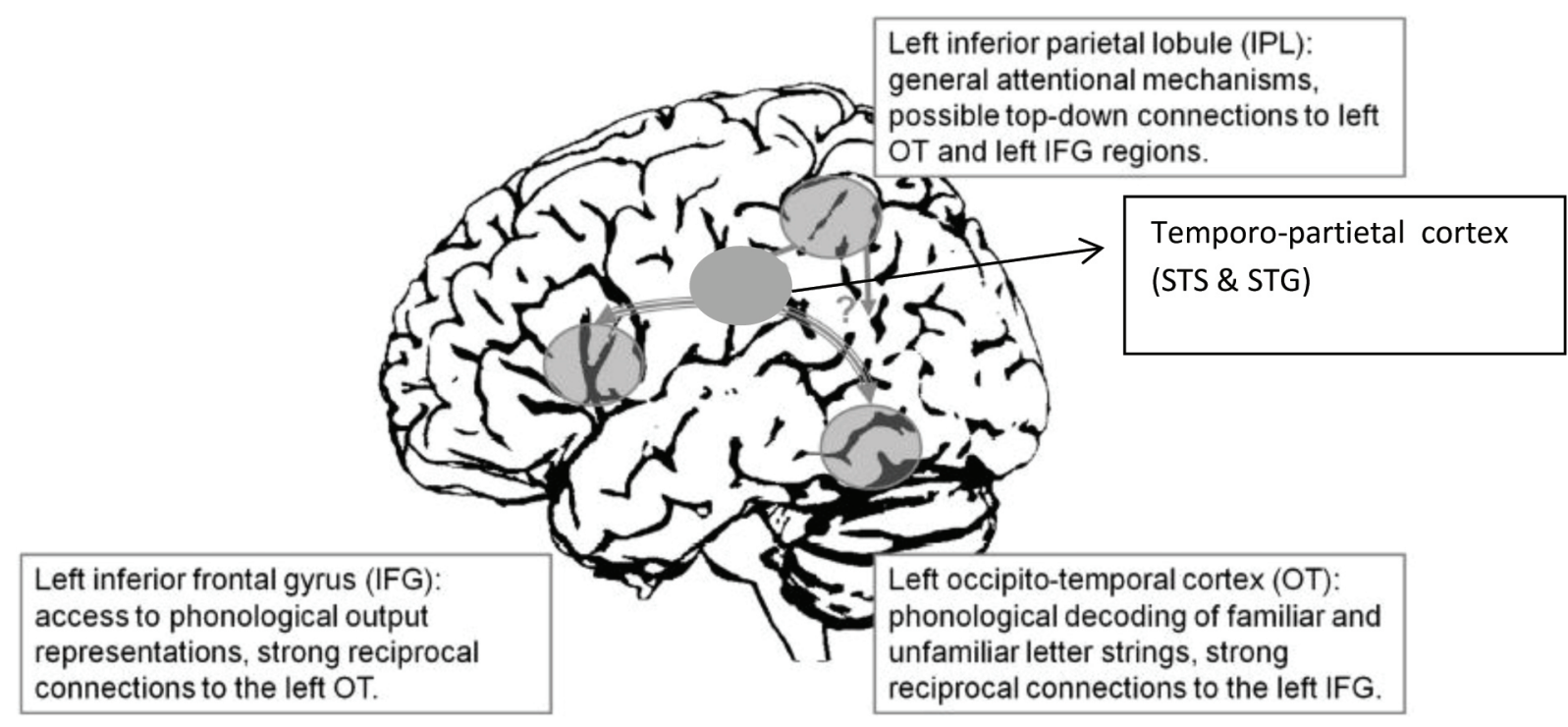

FIGURE 2 | Left-hemisphere reading network (adapted from Richlan, 2012, Figure 1). The graphemic representations (occipito-temporal cortex) are related to phonemic representations (frontal cortex: IFG) via grapheme-phoneme bindings (temporo-parietal cortex). Attentional mechanisms (IPL) might act upon both phonemic and graphemic representations.
Broca's area (Dufor et al., 2009). Inhibition is costly in terms of metabolic resources that then are not available for reading, a possible cause for the slow and laborious performance in word recognition and decoding that characterize dyslexia (Shaywitz and Shaywitz, 2005; Sprenger-Charolles et al., 2011). Reduced metabolic resources on reading might for instance slower the transmission of the phoneme percept from the frontal cortex to the areas of the temporo-parietal cortex that are responsible for grapheme-phoneme associations.

In summary, the processes involved in low-level reading skills are carried out by a neural network (Figure 2) that relates graphemic representations (occipito-temporal cortex) to phonemic representations (frontal cortex) via grapheme-phoneme bindings (temporo-parietal cortex). In turn, the three sources of dyslexia could be summarized as follows: a grapho-phonemic deficit due to a lack of strong and timely grapheme-phoneme associations, a graphemic deficit due to a failure to combine letters (or graphemes) into word representations, and an audiophonemic deficit arising from an allophonic mode of speech perception.

Each of these three possible core deficits has prompted attempts at remediation. Here we first review the results of the available remediation methods. We then see how the remediation of allophonic perception might contribute to overcome some of the limitations of these methods.

\section{REMEDIATION OF GRAPHEME-PHONEME ASSOCIATIONS}

As a failure to associate graphemes with phonemes is the most proximal cause of dyslexia, intervention studies should primarily aim to enable or improve the learning of grapho-phonemic associations. Not surprisingly, then, different kinds of graphophonemic training have been used in attempts to aid in reading acquisition and remediate dyslexia.
The results of a first meta-analysis (Ehri et al., 2001a, see also the results of the long-term longitudinal study of Johnson et al., 2012) indicate that systematic phonics instruction (mainly when based on grapheme-phoneme correspondences and not on rhyme units for instance) can improve the acquisition of low- and high-level reading skills, especially when training begins early and in children at risk for reading disability; the benefits of such training are lesser in children with reading disabilities (dyslexics). However, the results of two recent meta-analyses of training studies (McArthur et al., 2012; Galuschka et al., 2014) indicate that classical phonics instruction is the only treatment approach whose efficacy in children and adolescents with reading disabilities is statistically confirmed. Furthermore, as noted by Gabrieli (2009), only about $50 \%$ of dyslexics retain the reading progress they make after explicit and systematic instruction in decoding strategies and phonemic awareness, and those who do retain their gains do not attain the fluent reading competency of typical-reading children.

A new computerized phonics training program (GraphoGame) appears to be able to surpass the limits of classical phonics training programs, especially with regard to reading fluency. The aim of GraphoGame is to strengthen the binding between the orthographic and phonological encodings of words (for a review, Richardson and Lyytinen, 2014). The GraphoGame method is mainly based on the training of grapheme-phoneme correspondences. This method progresses from the simultaneous and repeated presentation of grapheme-phoneme correspondences (first in isolation, then included in syllables, and afterward in words) to fluency training with words and sentences. GraphoGame's effectiveness in improving reading acquisition has been demonstrated in several studies conducted in languages with various levels of orthographic transparency: Finnish 

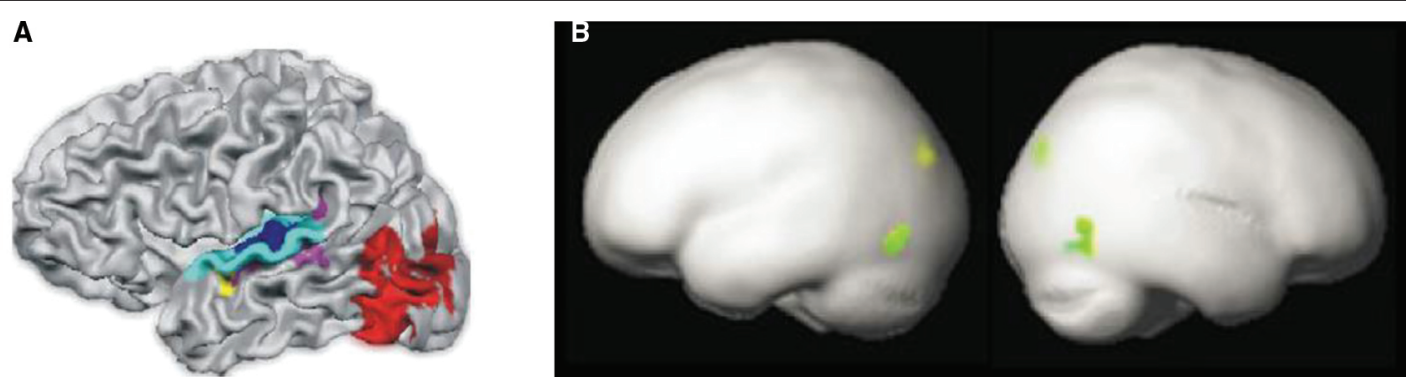

FIGURE 3 | (A) Letter-sound association area (in blue) and WWFA (in red) in the left STS-STG (adapted from Blomert, 2011, Figure 1). (B) GraphoGame training effects (in green; adapted from Brem et al., 2010, Figure 2).

(Saine et al., 2010, 2011), German (Brem et al., 2010), and English (Kyle et al., 2013).

In the Finnish study, after a screening of 166 first graders [with tests assessing letter knowledge, phonological awareness, and rapid automatic naming (RAN) of letters, digits, or pictures of frequent words], the lowest-achieving 30\% were randomly assigned to two different remedial interventions ( 25 children in each group): a regular remedial phonics intervention (RRI; Note ${ }^{2}$ ) or a computerized assisted intervention using GraphoGame (computer assisted regular remedial intervention, CARRI), both with four weekly sessions of $45 \mathrm{~min}$ for 28 weeks. These two groups were compared to the remaining children, who received "mainstream" reading instruction. For word reading fluency, at the end of the first grade, the CARRI group outperformed the RRI group, while both differed from the mainstreamers. One year later the difference between the CARRI group and the RRI group was still significant, but not the one between the CARRI group and the mainstreamers. Moreover, at that time, only three children from the CARRI group (11\%) still presented a severe deficit in word reading fluency, versus 11 children from the RRI group (44\%). Although these data are drawn from on a small number of participants, they are of interest, especially those from the RRI group, which are very similar to those reported by Gabrieli (2009) about the percentage of dyslexics who are "resistant" to classical phonological interventions. In addition, the CARRI group's gradual gains in word reading fluency indicate that children at risk for reading disability can reach the level of mainstream students. However, they require much more time to reach that level. These Finnish results were replicated in a language with a non-transparent orthography (English, Kyle et al., 2013). However, the interpretation of the results of that study is limited by the fact that no individual data were provided and no fluency evaluations were performed.

In another training study (Brem et al., 2010), functional magnetic resonance imaging (fMRI) data were collected from 16 German-speaking kindergarteners from Switzerland trained with both GraphoGame and a non-linguistic number-knowledge control game (duration of each of the two training programs: less than $4 \mathrm{~h}$ per week over 8 weeks). The results showed that

${ }^{2}$ The RRI included activities linking reading, spelling and phonology, training of word segmentation, training of decoding and spelling, and vocabulary training. behavioral improvements were accompanied by activity changes in the VWFA in the left occipito-temporal cortex (Figure 3). This contrasts with (later) findings by Blomert (2011) showing that the neural site of letter-speech sound bindings is located in the left temporal cortex suggesting that the results of a graphophonemic training method such as GraphoGame should primarily affect the letter-sound area. An effect of grapho-phonemic training on the VWFA is not surprising because the development of that areas depends on reading instruction (Dehaene et al., 2010). However, it nevertheless seems that GraphoGame should primarily impact the neural site of letter-speech sound bindings. One possible explanation to this discrepancy is that in Brem's study the effects of GraphoGame were assessed by comparing sensitivity to letters vs. other visual symbols. Possible changes in the sensitivity to letter-sound bindings, that should take place in temporo-parietal cortex, were thus not directly evaluated.

Instead of directly arising from a deficit with complex written symbols, the deficit in visual-auditory integration might arise from remote lower-level deficits. Training 7-year-old dyslexic children to associate elementary sound features (e.g., duration) with simple visual features (e.g., length) has been found to have positive effects on reading skills (Kujala et al., 2001). A recent study evidenced impaired audio-visual integration of low-level stimuli in dyslexic adults (Harrar et al., 2014). However, another recent study with adolescent dyslexics found that they exhibited specific problems with grapho-phonemic conversions even though their basic audio-visual integration mechanisms seemed to be intact (Kronschnabel et al., 2014). Whatever conclusions are ultimately drawn on this point, remediation methods might benefit from a better understanding of the processes involved in graphemephoneme integration.

\section{REMEDIATION OF VISUO-GRAPHEMIC DEFICIENCIES}

There have been several attempts to remediate graphemic deficits in dyslexia through the facilitation of low-level visual processing. A study with Italian and French children with dyslexia (Zorzi et al., 2012) showed that simple exposure to enhanced letter spacing led to improved reading accuracy and speed in both linguistic groups ( 34 to 40 children with dyslexia per language group, about 10 years old, 2-month follow-up). However, a subsequent study with Spanish children (Perea et al., 2012) found that the reading speed of children with dyslexia after exposure to enhanced letter 
spacing remained lower than that of typical readers (18 children with dyslexia, about 12 years old). This limitation might be due to the fact that the existing visuo-graphemic interventions do not tap into the perception of letters as visual categories. Letter enhancement taps into low-level visual processing, so that it magnifies not only the distinctions between letters that are relevant for word decoding, but also a host of graphical details that do not contribute to letter recognition.

Other remediation studies have aimed at improving visuoattentional performance using video games (e.g., Green and Bavelier, 2012). Franceschini et al. (2013), used "action" and "non-action" video games, differing in cognitive load and speed requirements, and compared their effects on reading. Two groups of 10 Italian children with dyslexia, of about 10 years of age, were randomly assigned to the "action" and "non-action" training groups (12 h at $80 \mathrm{~min}$ per day). The results showed significant improvement in reading performance only with the "action" training. When measured with a speed/accuracy score, the resulting progress in reading was equivalent to one year of spontaneous reading development. However, the study participants did not seem to present phonological deficits, meaning that the benefits of visuo-attentional training cannot be generalized to the whole dyslexic population. More importantly, studies in this area are still too rare to allow generalizations.

\section{REMEDIATION OF PHONOLOGICAL DEFICIENCIES INTERVENTIONS AIMED AT IMPROVING PHONEMIC AWARENESS}

Meta-analyses indicate that early phonemic awareness training helps children at risk for reading disability to acquire word-level reading skills, but such training has lesser effects in those who have already developed reading difficulties (Ehri et al., 2001b; National Institute for Literacy, 2008). These meta-analyses also highlight the fact that such training is very effective only when the letters (or graphemes) are presented together with the corresponding phonemes: remediation methods that train phonemic awareness alone have a limited impact on reading, and especially fluent reading. Furthermore, interventions using both graphemephoneme training and phonemic awareness training have neural effects in the left hemisphere reading network (Démonet et al., 2004), including the VWFA (Brem et al., 2010).

\section{INTERVENTIONS AIMED AT IMPROVING LOW-LEVEL AUDITORY PROCESSES}

Numerous auditory training methods have been proposed (for a review, Collet et al., 2014). For instance, Earobics ${ }^{\circledR}$ (Morrison, 1998; Diehl, 1999) is a computer-assisted training program which aims to improve reading skills by improving children's sound perception, memory, and phonological awareness. This program consists of a number of tasks, such as phoneme identification and discrimination and rhyme judgments. It has been widely used in the teaching of reading in American schools, but also in children with language learning difficulties specifically. Using this program with dyslexic children, Russo et al. (2005) showed a significant improvement of neural synchrony in the auditory brainstem in children who had received the training, while those who had not received this training showed no such changes. These results suggest that dyslexic children derive some benefits from this training, and that these benefits are also seen at the level of subcortical structures.

In the same vein, other studies have attempted to develop procedures to improve the auditory-perceptual abilities of children with learning disabilities. Merzenich et al. (1996) and Tallal et al. (1996), hypothesized that dyslexic children have a temporal processing disorder that could be remediated through auditory training, developed a computerized training program known as Fast ForWord ${ }^{\circledR}$ (Scientific Learning Corporation, Oakland, CA, USA). The program consisted in a succession of tasks such as the comparison or identification of sounds, phonemes, syllables, and words with variations in acoustic parameters such as duration and frequency, and was recommended during a period of 6 to 8 weeks (100 min a day, 5 days a week). Tallal et al. (1996) found that such auditory training had positive effects on the perception and understanding of speech. However, meta-analytic reviews indicate that these remediation attempts do not have reliable effects on reading performance (e.g., Strong et al., 2011).

\section{INTERVENTIONS AIMED AT REMEDIATING ALLOPHONIC PERCEPTION}

Contrary to typical phonemic perception, which combines different auditory features and weights them differently as a function of contextual features, allophonic perception uses these features independently and irrespective of context. For instance, French dyslexic children are sensitive to two different features that are perceived independently by the pre-linguistic child but are dynamically combined for separating voiced and voiceless consonants in French, with weights depending on the syllabic context (Bogliotti et al., 2008). Remediation of allophonic perception is intrinsically difficult, because it means modifying processes that allow the child to perceive speech sounds, albeit in a non-optimal way. There is no need to tap into auditory processes to remediate allophonic perception, because the use of allophonic units is not a matter of auditory feature perception as such but a matter of combining auditory features in way that is relevant for speech perception.

Discriminant training of minimal pairs (Hurford, 1990; Hurford and Sanders, 1990; Veuillet et al., 2007) might be of some help, but it has no straightforward implications for phonemic perception. Discriminating two different phonemes is supposed to be achieved with a phonemic boundary, but it can also be achieved through one of the several allophonic boundaries that separate these two phonemes. Similarly, the deletion of the initial phoneme from a word and other "phonemic awareness" performances are normally achieved with a phonemic cut-off point, but they can also be achieved with allophonic cut-off points. What is needed to remediate allophonic perception is to modify the boundaries that are used to discriminate and segment speech sounds, something that is not guaranteed with classical methods.

Until now, only a handful of studies have tried to remediate allophonic perception in people affected by dyslexia. Bogliotti (2005) trained severely impaired dyslexic children (five trained children and five untrained controls between 8 and 10 years of age) to identify allophonic variants of the same phoneme with the same label (following a procedure initiated by Guenther et al., 1999). The training improved the accuracy of phoneme identification, but it did not improve discrimination around the 


\section{A. Phonemic discrimination}

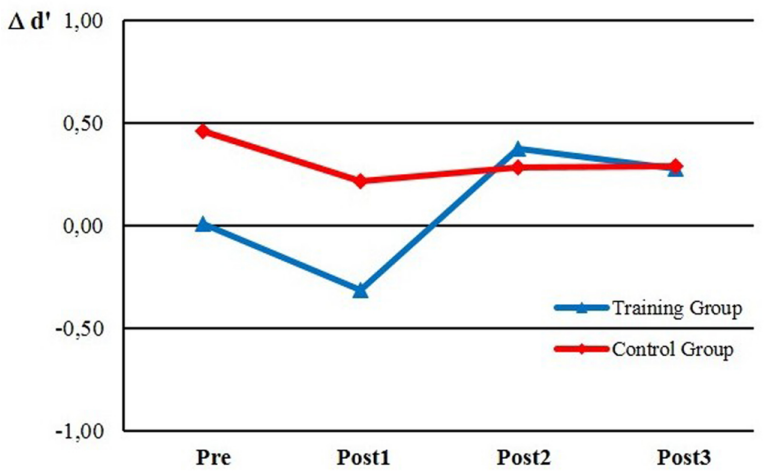

FIGURE 4 | Effects of phonemic discrimination training on SLI children with impaired reading skills: (1) on the difference in size (scaled in $d^{\prime}$; Macmillan and Creelman, 2005) between phonemic and allophonic discrimination peaks (A; adapted from Collet et al., 2012, Figures 3 and 4); and (2) on first phoneme elision performance, scored from 0 to 10

phoneme boundary. On the contrary, the training gave rise to discrimination peaks around allophonic boundaries. Allophonic discrimination was probably present in these children before training, but it only became apparent in behavioral responses after training. This suggests that allophonic perception is indeed highly resistant to training.

Recently, Collet et al. (2012) developed a new method, adapted from the "perceptual fading" training program (Jamieson and Morosan, 1986). The basic approach was to progressively reduce the acoustic distance between two stimuli as a function of each child's individual performance. This method aimed to teach children to discriminate fine acoustic differences between two different phonemes. During the study, the stimuli varied along a $\mathrm{d}$ /t t voice onset time (VOT) continuum, and the acoustic difference in VOT around the French VOT boundary was progressively reduced. At each stage, these pairs of different phonemes were mixed with other random pairs composed of identical phonemes. The task required the child to determine whether the pairs sounded alike or different. After each answer, the child received positive or negative visual feedback (green or red screen) on accuracy. As soon as the child's performance was stabilized above $75 \%$, the acoustic distance between phonemes was reduced in the next training step. This transition thus occurred when minimally distinct phonemes in acoustic terms were discriminated above chance level.

The total duration of the training was about $18 \mathrm{~h}(2 \times 9$ sessions of about $25 \mathrm{~min}$ each). Eighteen 9-year-old children with specific language impairment (SLI; which delays the mastery of oral language skills) who also had impaired reading and spelling skills (at least 1.5 standard deviations below the mean for their age) participated in the study. These children were randomly assigned to either a training group or a control group of equal size. Results showed that perceptual fading improved both discrimination and identification performance in these children. Allophonic discrimination peaks emerged after the initial training sessions, just as in the previous study with dyslexic

\section{B. First Phoneme Elision}

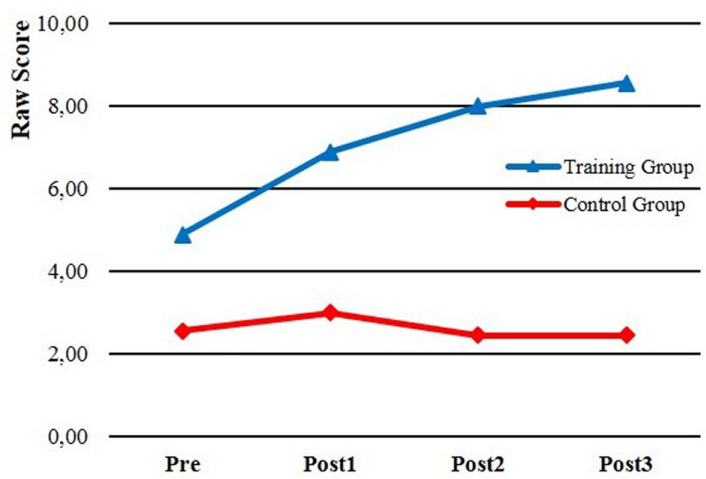

(B; adapted from Collet et al., 2012, Figure 6). Data were collected during four different sessions: for the training group, at the beginning of training (pre), in the middle of training (Post1), at the end of training (Post2), and 1 month post-training (Post3), and according to the same timeline for the control groups.

children (Bogliotti, 2005, see above), but they were progressively replaced by phonemic peaks in the later sessions (Figure 4). Importantly, phonemic awareness considerably improved after perceptual training. Unfortunately, reading performance was not evaluated at the end of the training.

Several important questions remain open concerning the impact of phonological remediation with perceptual fading (hereafter audio-phonological remediation, APR). One question is whether APR contributes to remediating reading deficits in dyslexia. The fact that the SLI children studied by Collet et al. (2012) also began with a reading deficit suggests that APR will also improve phonemic awareness in dyslexic children. And although there is presently no (published) evidence in support of the benefits of APR for reading, given the strong effects of APR on phonemic awareness it should also have at least some impact on reading performance. Preliminary results from APR training with dyslexic children suggest that this type of training is indeed beneficial for reading and spelling performance (work in progress).

Another question is whether APR truly transforms an allophonic system into a phonemic one. Recall that discrimination of allophonic peaks can be completely absent from behavioral responses even when it is present in neural processing (in children: Noordenbos et al., 2012b; in adults: Noordenbos et al., 2013). APR might thus give rise to a hybrid system that appears to be phonemic but that remains basically allophonic. Still another question is whether APR is beneficial for individuals with dyslexia who do not exhibit allophonic perception at the behavioral level although their neural processing is allophonic. Studies examining neural activity are needed to clarify these points.

\section{CONCLUSION}

Among the various methods that have been used in attempts to remediate dyslexia, those involving grapho-phonemic training are currently the most successful. However, as there are three possible sources of dyslexia (phonological, grapho-phonemic, and 
graphemic) several different methods need to be tried. Graphemic methods are successful in part of the dyslexic population. Phonological remediation based on phoneme awareness alone has only a limited effect on reading, especially in dyslexic children. A possible reason for these limitations is that training a child to manipulate phoneme-like segments does not guarantee a change in the way the child perceives these segments. Some recent studies suggest that a subset of people with dyslexia perceive speech in allophonic segments instead of phonemic ones, a distinction that is not captured by phoneme awareness tasks. A new method of phonological remediation that is specifically designed to change an allophonic mode of speech perception into a phonemic one is promising, although its effects on reading need to be confirmed.

\section{ACKNOWLEDGMENTS}

This work was supported by a public grant overseen by the French National Research Agency (ANR) as part of the "Investissements d'Avenir" program (reference: ANR-10-LABEX-0083). Many thanks to P. Reeve for proofreading the English manuscript.

\section{REFERENCES}

Blomert, L. (2011). The neural signature of orthographic-phonological binding in successful and failing reading development. Neuroimage 57, 695-703. doi: 10.1016/j.neuroimage.2010.11.003

Blomert, L., and Froyen, D. (2010). Multi-sensory learning and learning to read. Int. J. Psychophysiol. 77, 186-194. doi: 10.1016/j.ijpsycho.2010.06.025

Blomert, L., and Vaessen, A. (2009). 3DM Differentiaal Diagnose voor Dyslexie: Cognitieve Analyse van Lezen en Spelling [3DM Differential Diagnostics for Dyslexia: Cognitive Analysis of Reading and Spelling]. Amsterdam: Boom Test Publishers.

Bogliotti, C. (2005). Perception Allophonique et Dyslexie. [Allophonic Perception and Dyslexia]. Ph.D. thesis, Université Denis Diderot-Paris 7, Paris.

Bogliotti, C., Serniclaes, W., Messaoud-Galusi, S., and Sprenger-Charolles, L. (2008). Discrimination of speech sounds by dyslexic children: comparisons with chronological age and reading level controls. J. Exp. Child Psychol. 101, 137-175. doi: 10.1016/j.jecp.2008.03.006

Brem, S., Bach, S., Kucian, K., Guttorm, T. K., Martin, E., Lyytinen, H., et al. (2010). Brain sensitivity to print emerges when children learn letter-speech sound correspondences. Proc. Natl. Acad. Sci. U.S.A. 107, 7939-7944. doi: 10.1073/pnas. 0904402107

Cohen, L., and Dehaene, S. (2004). Specialization in the ventral stream: the case for the visual word form area. Neuroimage 22, 466-476. doi: 10.1016/j.neuroimage. 2003.12.049

Collet, G., Colin, C., Serniclaes, W., Hoonhorst, I., Markessis, E., Deltenre, P., et al. (2012). Effect of phonological training in French children with SLI: perspectives on voicing identification, discrimination and categorical perception. Res. Dev. Disabil. 33, 1805-1818. doi: 10.1016/j.ridd.2012.05.003

Collet, G., Leybaert, J., Serniclaes, W., Markessis, E., Hoonhorst, I., Deltenre, P., et al. (2014). Les entraînements auditifs: entre modifications comportementales et neurophysiologiques [Auditory trainings: between behavioral and neurophysiological modifications]. Année Psychol. 114, 389-418. doi: 10.4074/ S0003503314002073

Dehaene, S. (2014). Reading in the brain revised and extended: response to comments. Mind Lang. 29, 320-335. doi: 10.1111/mila.12053

Dehaene, S., Pegado, F., Braga, L. W., Ventura, P., Nunes-Filho, G., Jobert, A., et al. (2010). How learning to read changes the cortical networks for vision and language. Science 330, 1359-1364. doi: 10.1126/science.1194140

Démonet, J.-F., Taylor, M. J., and Chaix, Y. (2004). Developmental dyslexia. Lancet 363, 1451-1460. doi: 10.1016/S0140-6736(04)16106-0

Diehl, S. (1999). Listen \& Learn? A software approach review of Earobics. Lang. Speech Hear. Serv. Sch. 30, 108-116. doi: 10.1044/0161-1461.3001.108

Dufor, O., Serniclaes, W., Sprenger-Charolles, L., and Démonet, J.-F. (2009). Left pre-motor cortex and allophonic speech perception in dyslexia: a PET study. Neuroimage 46, 241-248. doi: 10.1016/j.neuroimage.2009.01. 035
Ehri, L. C., Nunes, S. R., Stahl, S. A., and Willows, D. M. (2001a). Systematic phonics instruction helps students learn to read: evidence from the National Reading Panel's meta-analysis. Rev. Educ. Res. 71, 393-447. doi: 10.3102/ 00346543071003393

Ehri, L. C., Nunes, S. R., Willows, D., Schuster, B. V., Yaghoub-Zadeh, Z., Shanahan, T., et al. (2001b). Phonemic awareness instruction helps children learn to read: evidence from the National Reading Panel's meta-analysis. Read. Res. Q. 36, 250 283. doi: $10.1598 /$ RRQ.36.3.2

Franceschini, S., Gori, S., Ruffino, M., Pedrolli, K., and Facoetti, A. (2012). A causal link between visual spatial attention and reading acquisition. Curr. Biol. 22, 814819. doi: 10.1016/j.cub.2012.03.013

Franceschini, S., Gori, S., Ruffino, M., Viola, S., Molteni, M., and Facoetti, A. (2013). Action video games make dyslexic children read better. Curr. Biol. 23, 462-466. doi: 10.1016/j.cub.2013.01.044

Froyen, D., Willems, G., and Blomert, L. (2011). Evidence for a specific crossmodal association deficit in dyslexia: an electrophysiological study of letterspeech sound processing. Dev. Sci. 14, 635-648. doi: 10.1111/j.1467-7687.2010. 01007.x

Gabrieli, J. D. E. (2009). Dyslexia: a new synergy between education and cognitive neuroscience. Science 325, 280-283. doi: 10.1126/science.1171999

Galuschka, K., Ise, E., Krick, K., and Schulte-Körne, G. (2014). Effectiveness of treatment approaches for children and adolescents with reading abilities: a meta-analysis of randomized control trials. PLoS ONE 9:e89900. doi: 10.1371/ journal.pone. 0089900

Green, C. S., and Bavelier, D. (2012). Learning, attentional control, and action video games. Curr. Biol. 22, R197-R206. doi: 10.1016/j.cub.2012.02.012

Guenther, F. H., Husain, F. T., Cohen, M. A., and Shinn-Cunningham, B. G. (1999). Effects of categorization and discrimination training on auditory perceptual space. J. Acoust. Soc. Am. 106, 2905-2912. doi: 10.1121/1.428112

Harrar, V., Tammam, J., Perez-Bellido, A., Pitt, A., Stein, J., and Spence, C. (2014). Multisensory integration and attention in developmental dyslexia. Curr. Biol. 24, 531-535. doi: 10.1016/j.cub.2014.01.029

Hurford, D. P. (1990). Training phonemic segmentation ability with a phonemic discrimination intervention in second- and third-grade children with reading disabilities. J. Learn. Dis. 23, 564-569. doi: 10.1177/002221949002300906

Hurford, D. P., and Sanders, R. E. (1990). Assessment and remediation of a phonemic discrimination deficit in reading disabled second and fourth graders. J. Exp. Child Psychol. 50, 396-415. doi: 10.1016/0022-0965(90)90077-L

Jamieson, D. G., and Morosan, D. E. (1986). Training non-native speech contrasts in adults: acquisition of the English $/ \partial /-\mid \theta /$ contrast by francophones. Atten. Percept. Psychophys. 40, 205-215. doi: 10.3758/BF03211500

Johnson, R. S., McGeown, S., and Watson, J. E. (2012). Long-term effects of synthetic versus analytic phonics teaching on the reading and spelling ability of 10 year old boys and girls. Read. Writ. 25, 1365-1384. doi: 10.1007/s11145-0119323-x

Kronschnabel, J., Brem, S., Maurer, U., and Brandeis, D. (2014). The level of audiovisual print-speech integration deficits in dyslexia. Neuropsychologia 62, 245-261. doi: 10.1016/j.neuropsychologia.2014.07.024

Kujala, T., Karma, K., Ceponiene, R., Belitz, S., Turkkila, P., Tervaniemi, M., et al. (2001). Plastic neural changes and reading improvement caused by audiovisual training in reading-impaired children. Proc. Natl. Acad. Sci. U.S.A. 98, 1050910514. doi: 10.1073/pnas. 181589198

Kyle, F. E., Kujala, J., Richardson, U., Lyytinen, H., and Goswami, U. (2013). Assessing the effectiveness of two theoretically motivated computer assisted reading interventions in the United Kingdom: GG Rime and GG Phoneme. Read. Res. Q. 48, 61-76. doi: 10.1002/rrq.038

Lachmann, T., and van Leeuwen, C. (2014). Reading as functional coordination: not recycling but a novel synthesis. Front. Psychol. 5:1046. doi: 10.3389/fpsyg. 2014.01046

Liberman, I., Shankweiler, D., Fischer, F., and Carter, B. (1974). Explicit syllable and phoneme segmentation in the young child. J. Exp. Child Psychol. 18, 201-212. doi: 10.1016/0022-0965(74)90101-5

Lobier, M., Zoubrinetzky, R., and Valdois, S. (2012). The visual attention span deficit in dyslexia is visual and not verbal. Cortex 48, 768-773. doi: 10.1016 / j.cortex.2011.09.003

Lyon, G. R., Shaywitz, S. E., and Shaywitz, B. A. (2003). A definition of dyslexia. Ann. Dyslexia 53, 1-14. doi: 10.1007/s11881-003-0001-9

Macmillan, N. A., and Creelman, C. D. (2005). Detection Theory: A User's Guide. London: Lawrence Erlbaum. 
McArthur, G., Eve, P. M., Jones, K., Banales, E., Kohnen, S., Anandakumar, T., et al. (2012). Phonics training for English-speaking poor readers. Cochrane Database. Syst. Rev. 12, CD009115. doi: 10.1002/14651858.CD009115.pub2

Melby-Lervåg, M., Lyster, S. A. H., and Hulme, C. (2012). Phonological skills and their role in learning to read: a meta-analytic review. Psychol. Bull. 138, 322-352. doi: $10.1037 / \mathrm{a} 0026744$

Merzenich, M. M., Jenkins, W. M., Johnston, P., Schreiner, C., Miller, S. L., and Tallal, P. (1996). Temporal processing deficits of language-learning impaired children ameliorated by training. Science 271, 77-81. doi: 10.1126/science.271. 5245.77

Messaoud-Galusi, S., Hazan, V., and Rosen, S. (2011). Investigating speech perception in children with dyslexia: is there evidence of a consistent deficit in individuals? J. Speech Lang. Hear. Res. 54, 1682-1701. doi: 10.1044/1092-4388 (2011/09-0261)

Morrison, S. (1998). Computer applications: Earobics Pro. Child Lang. Teach. Ther. 14, 279-284. doi: 10.1191/026565998669702253

National Institute for Literacy. (2008). Developing Early Literacy: Report of the Early Literacy Panel: A Scientific Synthesis of Early Literacy Development and Implications for Intervention. Jessup, MD: National Institute for Literacy.

Noordenbos, M., Segers, E., Serniclaes, W., Mitterer, H., and Verhoeven, L. (2012a). Allophonic mode of speech perception in children at-risk for dyslexia: a longitudinal study. Res. Dev. Disabil. 33, 1469-1483. doi: 10.1016/j.ridd.2012.03 .021

Noordenbos, M., Segers, E., Serniclaes, W., Mitterer, H., and Verhoeven, L. (2012b). Neural evidence of allophonic perception in children at risk for dyslexia. Neuropsychologia 50, 2010-2017. doi: 10.1016/j.neuropsychologia.2012.04. 026

Noordenbos, M. W., Segers, E., Serniclaes, W., and Verhoeven, L. (2013). Neural evidence of the allophonic mode of speech perception in adults with dyslexia. Clin. Neurophysiol. 124, 1151-1162. doi: 10.1016/j.clinph.2012.12.044

Perea, M., Panadero, V., Moret-Tatay, C., and Pablo Gómez, P. (2012). The effects of inter-letter spacing in visual-word recognition: evidence with young normal readers and developmental dyslexics. Learn. Instr. 22, 420-430. doi: 10.1016/j.learninstruc.2012.04.001

Peterson, R. L., and Pennington, B. F. (2012). Developmental dyslexia. Lancet 379, 1997-2007. doi: 10.1016/S0140-6736(12)60198-6

Richardson, U., and Lyytinen, H. (2014). The GraphoGame method: the theoretical and methodological background of the technology-enhanced learning environment for learning to read. Hum. Technol. 10, 39-60. doi: 10.17011/ht/urn.201405281859

Richlan, F. (2012). Developmental dyslexia: dysfunction of a left hemisphere reading network. Front. Hum. Neurosci. 6:120. doi: 10.3389/fnhum.2012.00120

Russo, N. M., Nicol, T. G., Zecker, S. G., Hayes, E. A., and Kraus, N. (2005). Auditory training improves neural timing in the human brainstem. Behav. Brain Res. 156, 95-103. doi: 10.1016/j.bbr.2004.05.012

Saine, N. L., Lerkkanen, M.-K., Ahonen, T., Tolvanen, A., and Lyytinen, H. (2010). Predicting word-level reading fluency outcomes in three contrastive groups: remedial and computer-assisted remedial reading intervention, and mainstream instruction. Learn. Indiv. Differ. 20, 402-414. doi: 10.1016/j.lindif.2010.06. 004

Saine, N. L., Lerkkanen, M.-K., Ahonen, T., Tolvanen, A., and Lyytinen, H. (2011). A computer-assisted remedial reading intervention for school beginners at-risk for reading disability. Child Dev. 82, 1013-1028. doi: 10.1111/j.14678624.2011.01580.x
Serniclaes, W., and Sprenger-Charolles, L. (2015). "Reading impairment: from behavior to brain," Handbook of Communication Disorders, eds R. Bahr and E. Silliman (London: Routledge).

Serniclaes, W., Van Heghe, S., Mousty, P., Carré, R., and Sprenger-Charolles, L. (2004). Allophonic mode of speech perception in dyslexia. J. Exp. Child Psychol. 87, 336-361. doi: 10.1016/j.jecp.2004.02.001

Shaywitz, S. E., and Shaywitz, B. A. (2005). Dyslexia (specific reading disability). Biol. Psychiatry 57, 1301-1309. doi: 10.1016/j.biopsych.2005.01.043

Shaywitz, S. E., Shaywitz, B. A., Fletcher, J. M., and Escobar, M. D. (1990). Prevalence of reading disability in boys and girls. Results of the Connecticut Longitudinal Study. JAMA 264, 998-1002. doi: 10.1001/jama.1990.03450080084036

Sprenger-Charolles, L., Colé, P., and Serniclaes, W. (2006). Reading Acquisition and Developmental Dyslexia. New York: Psychology Press. (New Edn. 2013).

Sprenger-Charolles, L., Siegel, L. S., Jiménez, J. E., and Ziegler, J. C. (2011). Prevalence and reliability of phonological, surface, and mixed profiles in dyslexia: a review of studies conducted in languages varying in orthographic depth. Sci. Stud. Read. 15, 498-521. doi: 10.1080/10888438.2010.524463

Strong, G. K., Torgerson, C. J., Torgerson, D., and Hulme, C. (2011). A systematic meta-analytic review of evidence for the effectiveness of the 'Fast ForWord' language intervention program. J. Child Psychol. Psychiatry 52, 224-235. doi: 10.1111/j.1469-7610.2010.02329.x

Tallal, P., Miller, S., Bedi, G., Byma, G., Wang, X., Nagarajan, S. S., et al. (1996). Language comprehension in language-learning impaired children improved with acoustically modified speech. Science 271, 81-84. doi: 10.1126/science.271. 5245.81

van Atteveldt, N., Formisano, E., Goebel, R., and Blomert, L. (2004). Integration of letters and speech sounds in the human brain. Neuron 43, 1-12. doi: 10.1016/ j.neuron.2004.06.025

Veuillet, E., Magnan, A., Ecalle, J., Thai-Van, H., and Collet, L. (2007). Auditory processing disorder in children with reading disabilities: effect of audiovisual training. Brain 130, 2915-2928. doi: 10.1093/brain/awm235

Vogel, A. C., Petersen, S. E., and Schlaggar, B. L. (2014). The VWFA: it's not just for words any more. Front. Hum. Neurosci. 8:88. doi: 10.3389/fnhum.2014.00088

Zorzi, M., Barbiero, C., Facoetti, A., Lonciari, I., Carrozzi, M., Montico, M., et al. (2012). Extra-large letter spacing improves reading in dyslexia. Proc. Natl. Acad. Sci. U.S.A. 109, 11455-11459. doi: 10.1073/pnas.1205566109

Conflict of Interest Statement: The authors declare that the research was conducted in the absence of any commercial or financial relationships that could be construed as a potential conflict of interest.

Received: 16 September 2014; accepted: 05 February 2015; published online: 24 February 2015.

Citation: Serniclaes W, Collet G and Sprenger-Charolles L (2015) Review of neural rehabilitation programs for dyslexia: how can an allophonic system be changed into a phonemic one? Front. Psychol. 6:190. doi: 10.3389/fpsyg.2015.00190

This article was submitted to Cognitive Science, a section of the journal Frontiers in Psychology.

Copyright (C) 2015 Serniclaes, Collet and Sprenger-Charolles. This is an open-access article distributed under the terms of the Creative Commons Attribution License (CC $B Y)$. The use, distribution or reproduction in other forums is permitted, provided the original author(s) or licensor are credited and that the original publication in this journal is cited, in accordance with accepted academic practice. No use, distribution or reproduction is permitted which does not comply with these terms. 